\title{
Risk factors for hypocalcemia and hypoparathyroidism following thyroidectomy: a retrospective Chinese population study
}

This article was published in the following Dove Press journal:

Cancer Management and Research

15 November 2017

Number of times this article has been viewed

\author{
Ying-hao Wang* \\ Adheesh Bhandari* \\ Fan Yang \\ Wei Zhang \\ Li-jun Xue \\ Hai-guang Liu \\ Xiao-hua Zhang \\ Cheng-ze Chen
}

Department of Surgical Oncology, The First Affiliated Hospital of Wenzhou Medical University, Wenzhou, People's Republic of China

*These authors contributed equally to this work
Correspondence: Cheng-ze Chen Department of Surgical Oncology, The First Affiliated Hospital of Wenzhou Medical University, Nanbai Xiang, Ouhai, Wenzhou, Zhejiang 325000, People's Republic of China

Tel +86 I59 587I 0052

Email cczltz@l63.com
Background: Hypocalcemia is one of the most common postoperative complications following thyroid surgery in clinical practice. The occurrence of hypocalcemia is mainly attributed to hypoparathyroidism when parathyroid glands are devascularized, injured, or dissected during the surgery. The aim of this study was to analyze the risk factors for hypocalcemia and hypoparathyroidism following thyroidectomy.

Patients and methods: A total of 278 patients who underwent thyroid surgery were analyzed retrospectively. Univariate analysis and multivariable logistic regression were performed to discover the risk factors for hypocalcemia and hypoparathyroidism.

Results: Postoperative hypocalcemia occurred in 76 (27.3\%) patients and hypoparathyroidism occurred in $42(15.1 \%)$ patients. Seven factors were significantly related to the presence of postoperative hypocalcemia, namely, age $(P=0.049)$, gender $(P=0.015)$, lateral lymph node dissection $(P=0.017)$, operation type $(P<0.001)$, preoperative parathyroid hormone (PTH) level $(P=0.035)$, operation time $(P=0.001)$, and applying carbon nanoparticles (CNs; $P=0.007)$. Our result revealed that gender $(P=0.014)$, lateral lymph node dissection $(P=0.038)$, operation type $(P<0.001)$, operative time $(P<0.001)$, and applying $\mathrm{CNs}(P=0.001)$ had a significant correlation with postoperative hypoparathyroidism.

Conclusion: These findings were crucial for guiding surgeons to prevent the occurrence of hypocalcemia and hypoparathyroidism.

Keywords: hypocalcemia, hypoparathyroidism, thyroidectomy, risk factor

\section{Introduction}

Since the 1990s, the incidence of thyroid cancer has increased, faster than any other cancer type in the US. Over the past 3 decades, the incidence of thyroid cancer has increased $240 \%{ }^{1}$ Currently, there are 56,780 new thyroid cancer patients in the US. ${ }^{2}$ Although the mortality of thyroid cancer is not very high compared with other cancers, there are some subtypes of thyroid cancer that are more aggressive and needed more positive treatment.

Surgery and radioiodine therapy are the two main recommended approaches. Thyroidectomy is frequently recommended to patients with thyroid nodules, especially for those in whom thyroid cancer is suspected of carrying thyroid cancer. ${ }^{3,4}$ The completeness of surgical resection helps to improve survival and lower recurrence; thus, most surgeons proposed total thyroidectomy over thyroid lobectomy. ${ }^{5}$ However, compared with thyroid lobectomy, there is a higher incidence risk of complications after total thyroidectomy. Complications of these surgical procedures are numerous, 
and some of them are severe and persistent over time, ${ }^{6,7}$ including hypoparathyroidism, hypocalcemia, vocal paralysis, and hemorrhage. Transient hypocalcemia is one of the most common postoperative complications following thyroid surgery in clinical practice. ${ }^{8,9}$ It has been reported that the rate of postoperative transient hypocalcemia ranges from $6 \%$ to $30 \%,{ }^{10-12}$ although there is $\leq 2 \%$ incidence of persistent dysfunction. The nadir of hypocalcemia often appears within 48 hours after thyroidectomy. ${ }^{13,14}$ Symptoms are severe and, requiring calcium replacement therapy.

In many cases, serum calcium levels recover spontaneously within a few months. However, in a few patients, hypoparathyroidism persists after 1 year and may be considered permanent. ${ }^{15}$ The occurrence of permanent hypocalcemia is mainly attributed to postoperative hypoparathyroidism when parathyroid glands are devascularized, injured, or dissected during the surgery. ${ }^{15,16}$ The hypocalcemia after surgery is related to multiple factors, including surgical technique, the definition of hypocalcemia, criteria of report series, and use of prophylactic calcium supplementation in the perioperative period. ${ }^{16,17}$

Postoperative hypocalcemia can not only cause clinical symptoms but can also become a major contributing factor of prolonged hospitalization time for close observation and frequent laboratory evaluations. ${ }^{11,18}$ The aim of this study was to investigate the frequency and risk factors for postthyroidectomy hypocalcemia and hypoparathyroidism following thyroidectomy.

\section{Patients and methods Enrollment of patients}

We performed a retrospective analysis of patients who underwent total thyroidectomy or lobectomy surgery at The First Affiliated Hospital of Wenzhou Medical University from 2012 to 2014. During surgery, all or partial thyroid tissue was removed, including the posterior capsule and pyramidal lobe, varying upon patient condition. All parathyroid glands were identified. The viable parathyroids were identified and if possible preserved on an intact vascular pedicle, and those that appeared nonviable or could not be preserved were removed, placed in cold saline, and minced into $11 \mathrm{~mm}$ fragments; parathyroid slivers were autotransplanted to a muscle bed in the sternocleidomastoid or the nondominant forearm.

This study obtained ethical approval from the Institutional Review Board of First Affiliated Hospital of Wenzhou Medical University (approval no. 2012-57). In addition, the medical directors' offices of the hospital granted permission to use the patients' data for this study. All data had no personal identifiers and were kept confidential and therefore did not require informed consent.

A total number of 278 consecutive patients were finally enrolled with criteria as follows. The serum calcium and parathyroid hormone (PTH) level of patients were tested preoperatively and 48 hours after the operation, respectively. In our hospital, we routinely tested the preoperative PTH in order to exclude postoperative hypocalcemia and hypoparathyroidism. All patients were routinely supplemented with calcium through intravenous injection, and dose adjustment of calcium and appropriate amounts of vitamin D was managed based on clinical symptoms. In all, patients with symptoms of hypocalcemia or hypoparathyroidism occured for a period of 1 month after the surgery is usually temporary. If the symptoms were not alleviated after 6 months postoperatively, hypocalcemia or hypoparathyroidism symptoms could be seen as permanent. Hypocalcemia and hypoparathyroidism were diagnosed according to the American Thyroid Surgery Society 2009 guideline. ${ }^{19}$

There was a significant association between preoperative PTH and postoperative hypocalcemia and hypoparathyroidism.

Patients were finally enrolled with exclusion criteria as follows:

1. Patients had hypocalcemia or abnormal parathyroid function before the surgery.

2. Patients had a history of thyroid or neck surgery. All patients were operated on by Xiao-hua Zhang, Cheng-ze Chen, and Ying-hao Wang.

\section{Collection of clinicopathological parameters and study protocol}

Demographic, pathologic, and laboratory data of all enrolled patients were collected from electronic medical records. Clinicopathological data collected encompassed age, gender, and preoperative and postoperative corrected serum calcium and PTH levels. In addition, information on the type of operation, operative time, and intraoperative management of the parathyroid gland was obtained from the surgical records. Patients were defined as having hypocalcemia if the serum calcium value was $<2.0 \mathrm{mmol} / \mathrm{L} 48$ hours after an operation or related symptoms were present, and oral treatment with calcium and calcitriol was started if the serum calcium level dropped below this value. This selective therapeutic strategy allows for patients to be discharged home early on the next day and minimizes overtreatment of the normocalcemic patients. 
Among patients with hypocalcemia, we further defined them as with hypoparathyroidism, once the postoperative serum PTH value was $<15 \mathrm{pg} / \mathrm{mL}$.

\section{Application of carbon nanoparticle (CN) suspension injection}

$\mathrm{CN}$ suspension injection was applied in the form of a standard CN suspension injection ( $1 \mathrm{~mL}: 50 \mathrm{mg}$ ). The suspension does not enter the blood circulation and has no toxic side effects on the human body. ${ }^{20}$ The suspension comprises nanosized carbon particles with an average diameter of $150 \mathrm{~nm}$. The cell gap between capillary endothelial cells is 20-50 nm, and the capillary lymphatic endothelial cell gap is $120-500 \mathrm{~nm}$ with a hypoplasia of the basement membrane. Therefore, $\mathrm{CN}$ is unable to enter the blood vessels when it is injected into the thyroid tissue, and it will rapidly enter lymphatic vessels or the lymphatic capillaries through macrophage phagocytosis and be retained in the lymph nodes. The thyroid and lymph in their drainage areas are stained black in surgery. ${ }^{20}$ However, the parathyroid glands do not stain black, and hence, the black-stained thyroid and lymph nodes can be identified and are distinguished clearly. After cutting along the white cervical line, the thyroid gland can be identified carefully eliminating the false fibrous capsule from the thyroid gland and revealing the gland near the isthmus. Unnecessary freed gland can cause damage to the surrounding lymphatic network and influence the effects of $\mathrm{CNs}$ after injection. The integrity of the fibrous capsule of thyroid glands must be maintained. Damage of the fibrous capsule of thyroid glands can cause a leakage of CN suspension, resulting in the entire operative field stained black, which will render it impossible to distinguish the parathyroid gland and increase surgical risk. One injection of $0.1 \mathrm{~mL}$ $\mathrm{CN}$ suspension injection was administered with a fine needle in the lower one-third of the ventral surface to each of the bilateral glands, and the injection depth was roughly within the upper third of the glands. Too deep or shallow an injection can also cause the extravasation of $\mathrm{CN}$ suspension, which can result in a black-stained surgical field and increase the risk of surgery. All of the abovementioned factors are essential to take into consideration when performing the injection. Thus, the injection requires extra care. The needle must avoid the tumor, and the surgeon must proceed to inject slowly if no blood is found upon pump back during injection of the suspension. After injecting the needle, pressure must be applied for 1-2 minutes with a gauze and this allows the full staining of the suspension injection in the thyroid gland, parathyroid glands and lymph nodes.

\section{Statistical analysis}

Measurement data on normal distribution are expressed as the mean \pm standard deviation (SD) and were compared with the two-sample $t$-test. Categorical data are expressed as a percentage and were compared with chi-square test or Fisher's exact test, as appropriate. Logistic regression analysis was also performed to estimate the odds ratios (ORs) of certain parameters. A $P$ value of $<0.05$ was considered as statistically significant. Statistical analysis was performed with SPSS software version 22.0 (IBM Corp., Armonk, NY, USA).

\section{Results \\ Baseline characteristics}

A total of 278 patients who underwent thyroid operations were included in the study, including 218 women and 60 men. Table 1 lists the baseline clinicopathological characteristics

Table I Baseline characteristics of enrolled patients

\begin{tabular}{|c|c|}
\hline Variables & n (\%) \\
\hline Age (years), mean $\pm S D$ & $48 \pm I I$ \\
\hline \multicolumn{2}{|l|}{ Gender } \\
\hline Female & $218(78.42)$ \\
\hline Male & $60(21.58)$ \\
\hline \multicolumn{2}{|l|}{ Pathology } \\
\hline Benign & $81(29.14)$ \\
\hline Malignant & $197(70.86)$ \\
\hline \multicolumn{2}{|l|}{ Central lymph node dissection } \\
\hline No & $100(35.97)$ \\
\hline Yes & $178(64.03)$ \\
\hline \multicolumn{2}{|l|}{ Lateral lymph node dissection } \\
\hline No & $240(86.33)$ \\
\hline Yes & $38(13.67)$ \\
\hline \multicolumn{2}{|l|}{ Parathyroid inadvertent dissection } \\
\hline No & $247(88.85)$ \\
\hline Yes & $31(11.15)$ \\
\hline \multicolumn{2}{|l|}{ Operation } \\
\hline Lobectomy & I 37 (49.28) \\
\hline Lobectomy plus isthmusectomy & $62(22.30)$ \\
\hline Near-total thyroidectomy & $30(10.79)$ \\
\hline Total thyroidectomy & $49(17.63)$ \\
\hline \multicolumn{2}{|l|}{ Postoperative hypocalcemia } \\
\hline No & $202(72.66)$ \\
\hline Yes & $76(27.34)$ \\
\hline \multicolumn{2}{|l|}{ Postoperative hypoparathyroidism } \\
\hline No & $236(84.89)$ \\
\hline Yes & $42(15.11)$ \\
\hline No. of patients with parathyroid autotransplantation & $52(|8.7|)$ \\
\hline One parathyroid gland & $48(17.27)$ \\
\hline Two parathyroid glands & $4(\mathrm{I} .44)$ \\
\hline Inadvertent removal of the parathyroid glands & $31(11.15)$ \\
\hline One parathyroid gland in specimen & $30(10.79)$ \\
\hline Two parathyroid glands in specimen & $\mathrm{I}(0.36)$ \\
\hline
\end{tabular}

Abbreviation: SD, standard deviation. 
of enrolled patients. Postoperative hypocalcemia occurred in $76(27.3 \%)$ patients, and hypoparathyroidism occurred in $42(15.1 \%)$ patients. Table 2 lists the usage status of $\mathrm{CN}$ suspension injection in different operations.

Table 2 Usage status of $\mathrm{CN}$ suspension injection in different operations

\begin{tabular}{lll}
\hline Operation & \multicolumn{2}{l}{ CN suspension injection, $\mathbf{n}(\%)$} \\
\cline { 2 - 3 } & Yes $(\mathbf{n}=95)$ & No $(\mathbf{n}=183)$ \\
\hline Lobectomy & $45(47.37)$ & $92(50.27)$ \\
Lobectomy plus isthmusectomy & $13(13.68)$ & $49(26.78)$ \\
Near-total thyroidectomy & $6(6.32)$ & $24(13.11)$ \\
Total thyroidectomy & $31(32.63)$ & $18(9.84)$ \\
\hline
\end{tabular}

Abbreviation: $\mathrm{CN}$, carbon nanoparticle.

\section{Risk factors for postoperative hypocalcemia}

To discover potential risk factors for postoperative hypocalcemia, the patients were divided into two groups. Table 3 lists the differences in clinicopathological characteristics between the two groups. Among these, eight factors were significantly related to the presence of postoperative hypocalcemia, namely, age $(P=0.049)$, gender $(P=0.015)$, lateral lymph node dissection $(P=0.017)$, operation type $(P<0.001)$, preoperative PTH level $(P=0.035)$, operation time $(P=0.001)$, parathyroid autotransplantation $(P=0.002)$, and applying CNs $(P=0.007)$. However, pathology, central lymph node dissection, parathyroid inadvertent dissection, number of

Table 3 Univariate analysis for risk factors for postoperative hypocalcemia and hypoparathyroidism

\begin{tabular}{|c|c|c|c|c|c|c|c|c|}
\hline & \multicolumn{2}{|c|}{$\begin{array}{l}\text { Postoperative } \\
\text { hypocalcemia }\end{array}$} & \multirow[t]{2}{*}{$\chi^{2} / t$} & \multirow[t]{2}{*}{$P$-value } & \multicolumn{2}{|c|}{$\begin{array}{l}\text { Postoperative } \\
\text { hypoparathyroidism }\end{array}$} & \multirow[t]{2}{*}{$\chi^{2} / t$} & \multirow[t]{2}{*}{$P$-value } \\
\hline & No & Yes & & & No & Yes & & \\
\hline Number & 202 & 76 & & & 236 & 42 & & \\
\hline Age (years), mean $\pm S D$ & $47 \pm I I$ & $50 \pm 12$ & 1.976 & 0.049 & $47 \pm I I$ & $48 \pm 12$ & 0.535 & 0.592 \\
\hline Gender & & & 5.864 & 0.015 & & & 6.095 & 0.014 \\
\hline Female & $|5|$ & 67 & & & 179 & 39 & & \\
\hline Male & 51 & 9 & & & 57 & 3 & & \\
\hline Pathology & & & 1.506 & 0.239 & & & 1.424 & 0.272 \\
\hline Benign & 63 & 18 & & & 164 & 33 & & \\
\hline Malignant & 139 & 58 & & & 72 & 9 & & \\
\hline Central lymph node dissection & & & 2.240 & 0.161 & & & 2.055 & 0.167 \\
\hline No & 78 & 22 & & & 89 & 11 & & \\
\hline Yes & 124 & 54 & & & 147 & 31 & & \\
\hline Lateral lymph node dissection & & & 6.708 & 0.017 & & & 4.311 & 0.038 \\
\hline No & $|8|$ & 59 & & & 208 & 32 & & \\
\hline Yes & 21 & 17 & & & 28 & 10 & & \\
\hline Parathyroid inadvertent dissection & & & 1.165 & 0.290 & & & 2.246 & 0.134 \\
\hline No & 182 & 65 & & & 213 & 34 & & \\
\hline Yes & 20 & 11 & & & 23 & 8 & & \\
\hline Operation & & & 24.664 & 0.000 & & & 69.078 & 0.000 \\
\hline Lobectomy & 112 & 25 & & & 133 & 4 & & \\
\hline Lobectomy plus isthmusectomy & 49 & 13 & & & 58 & 4 & & \\
\hline Near-total thyroidectomy & 17 & 13 & & & 23 & 7 & & \\
\hline Total thyroidectomy & 24 & 25 & & & 22 & 27 & & \\
\hline Preoperative serum calcium level, mean \pm SD & $2.31 \pm 0.11$ & $2.29 \pm 0.10$ & 1.384 & 0.167 & $2.30 \pm 0.11$ & $2.32 \pm 0.10$ & 1.100 & 0.272 \\
\hline Preoperative PTH level, mean \pm SD & $34.34 \pm 10.21$ & $38.02 \pm 18.42$ & 2.109 & 0.035 & $35.49 \pm 10.96$ & $34.53 \pm 21.48$ & 0.438 & $0.66 \mathrm{I}$ \\
\hline Operative time (minutes), mean \pm SD & $66 \pm 27$ & $79 \pm 39$ & 3.144 & 0.001 & $66 \pm 25$ & $93 \pm 48$ & 5.452 & 0.000 \\
\hline CNs & & & 8.096 & 0.007 & & & 11.604 & 0.001 \\
\hline Injected & 59 & 36 & & & 71 & 24 & & \\
\hline Non-injected & 143 & 40 & & & 169 & 18 & & \\
\hline Parathyroid autotransplantation & & & 9.198 & 0.002 & & & 42.3 & 0.000 \\
\hline No & 173 & 53 & & & 207 & 19 & & \\
\hline Yes & 29 & 23 & & & 29 & 23 & & \\
\hline Inadvertent removal of the parathyroid glands & & & 1.165 & 0.28 & & & $\mathrm{~N}$ & 0.106 \\
\hline No & 182 & 65 & & & 213 & 34 & & \\
\hline Yes & 20 & 11 & & & 23 & 8 & & \\
\hline
\end{tabular}

Note: $\mathrm{N}$ indicates this group is not suitable for chi-square test but fisher exact test.

Abbreviations: SD, standard deviation; PTH, parathyroid hormone; CN, carbon nanoparticle. 
identified parathyroid glands, and preoperative serum calcium levels were not significantly correlated with the presence of postoperative hypocalcemia $(P>0.05)$. Multivariate analyses showed that age $(P=0.038)$, lateral lymph node dissection $(P=0.050)$, operation type $(P<0.001)$, and applying $\mathrm{CNs}$ $(P=0.036)$ were independent predictors for postoperative hypocalcemia (Table 4).

\section{Risk factors for postoperative hypoparathyroidism}

Next, we detected potential risk factors for postoperative hypoparathyroidism. Our results revealed that gender $(P=0.014)$, lateral lymph node dissection $(P=0.038)$, operation type $(P<0.001)$, operative time $(P<0.001)$, parathyroid autotransplantation $(P<0.001)$, and applying $\mathrm{CNs}(P=0.001)$ had a significant correlation with postoperative hypoparathyroidism (Table 3). Multivariate analysis showed that operation type $(P<0.001)$, gender $(P=0.026)$, and preoperative PTH level $(P=0.006)$ were independent predictors for postoperative hypoparathyroidism (Table 5).

\section{Discussion}

Hypocalcemia and hypoparathyroidism are a frequent complication of thyroidectomy with the growing incidence of thyroid disease..$^{21,22}$ The increased incidence of hypocalcemia in post-thyroidectomy patients may be attributed to hemodilution. Earlier studies also provide various other factors such as age, basic pathology, and duration of surgery as reasons for increased incidence of hypocalcemia..$^{23}$ When all glands are compromised by injury of the vascular pedicle, resection or unintended surgical manipulation and sudden significant fall in levels of PTH occur, leading to more intense and faster hypocalcemia, hence causing the symptoms. With partial preservation of the function of the parathyroid glands, the PTH decrease is less significant, remaining so until there is retrieval or repair of the remaining glands of the ischemic parathyroid cells. In such cases, the calcium concentration falls more slowly and with less intensity, lesser possible to cause clinical symptoms. Searching for parathyroid glands may, theoretically, increase the risk of them being injured, being a contributing factor to hypocalcemia. ${ }^{24,25}$

Hypocalcemia occurs secondary to hypoparathyroidism due to trauma, devascularization, or removal of the parathyroid glands that leads to prolonged hospitalization, increased medical cost, and patient discomfort. ${ }^{26,27}$ Therefore, it is necessary to find risk factors for hypocalcemia and hypoparathyroidism following thyroidectomy and to help guide clinical practice.

Table 4 Multivariable logistic regression for risk factors for postoperative hypocalcemia

\begin{tabular}{|c|c|c|c|c|c|c|c|}
\hline \multirow[t]{2}{*}{ Variables } & \multirow[t]{2}{*}{ Coefficient } & \multirow{2}{*}{$\begin{array}{l}\text { Standard } \\
\text { error }\end{array}$} & \multirow{2}{*}{$\begin{array}{l}\text { Wald } \\
\text { value }\end{array}$} & \multirow[t]{2}{*}{ P-value } & \multirow[t]{2}{*}{ OR } & \multicolumn{2}{|l|}{$95 \% \mathrm{Cl}$} \\
\hline & & & & & & Lower & Upper \\
\hline Age (years) & 0.028 & 0.013 & 4.298 & 0.038 & 1.028 & 1.002 & 1.055 \\
\hline \multicolumn{8}{|l|}{ Lateral lymph node dissection } \\
\hline Yes versus no & 0.759 & 0.388 & 3.832 & 0.050 & 2.137 & 0.999 & 4.570 \\
\hline Operation & & & & 0.000 & & & \\
\hline Lobectomy plus isthmusectomy versus lobectomy & 0.161 & 0.392 & 0.168 & 0.682 & 1.174 & 0.545 & 2.531 \\
\hline Near-total thyroidectomy versus lobectomy & 1.388 & 0.441 & 9.904 & 0.002 & 4.005 & 1.688 & 9.503 \\
\hline Total thyroidectomy versus lobectomy & 1.310 & 0.378 & 12.035 & 0.001 & 3.708 & 1.768 & 7.774 \\
\hline \multicolumn{8}{|l|}{$\mathrm{CNs}$} \\
\hline Injected versus non-injected & 0.644 & 0.308 & 4.375 & 0.036 & 1.904 & 1.041 & 3.480 \\
\hline
\end{tabular}

Abbreviations: OR, odds ratio; $\mathrm{CN}$, carbon nanoparticle.

Table 5 Multivariable logistic regression for risk factors for postoperative hypoparathyroidism

\begin{tabular}{|c|c|c|c|c|c|c|c|}
\hline \multirow[t]{2}{*}{ Variables } & \multirow[t]{2}{*}{ Coefficient } & \multirow{2}{*}{$\begin{array}{l}\text { Standard } \\
\text { error }\end{array}$} & \multirow{2}{*}{$\begin{array}{l}\text { Wald } \\
\text { value }\end{array}$} & \multirow[t]{2}{*}{$P$-value } & \multirow[t]{2}{*}{ OR } & \multicolumn{2}{|l|}{$95 \% \mathrm{Cl}$} \\
\hline & & & & & & Lower & Upper \\
\hline \multicolumn{8}{|l|}{ Gender } \\
\hline Male versus female & -1.583 & 0.709 & 4.988 & 0.026 & 0.205 & 0.051 & 0.824 \\
\hline Preoperative PTH level & -0.066 & 0.024 & 7.528 & 0.006 & 0.936 & 0.894 & 0.981 \\
\hline Operation & & & & 0.000 & & & \\
\hline Lobectomy plus isthmusectomy versus lobectomy & 0.619 & 0.735 & 0.709 & 0.400 & 1.857 & 0.440 & 7.844 \\
\hline Near-total thyroidectomy versus lobectomy & 2.352 & 0.688 & 11.676 & 0.001 & 10.502 & 2.726 & 40.466 \\
\hline Total thyroidectomy versus lobectomy & 3.799 & 0.609 & 38.946 & 0.000 & 44.647 & $|3.54|$ & | 47.207 \\
\hline
\end{tabular}

Abbreviations: OR, odds ratio; PTH, parathyroid hormone. 
In this study, we performed a retrospective analysis of 278 patients and used statistical tools to analyze clinical data. Collectively, our results demonstrate that gender, lateral lymph node dissection, operation type, operation time, and use of CNs were related to the occurrence of hypocalcemia and hypoparathyroidism.

In 2012, "Management Guidelines of Thyroid Nodules and Differentiated Thyroid Cancer" was made by Chinese Society of Endocrinology, Chinese Society of Surgery, China, Anti-Cancer Association of Head and Neck Specialized Committee, and Chinese Society of Nuclear Medicine depending on management guidelines made by American Thyroid Association (ATA), European Society for Medical Oncology (ESMO), and American Association of Clinical Endocrinologists (AACE). In this guideline, it recommended prophylactic central lymph nodes dissection with the preservation of recurrent laryngeal nerve and parathyroid glands. According to this guideline, whether to perform dissection of central lymph nodes depends on pathologic characteristics and surgeon skills, rather than surgery type. Surgery type is more dependent on tumor size, single or multiple nodules, invasion of adjacent tissues, lymphatic metastasis, metastasis, radiation in childhood, family history of thyroid cancer or subtype, and so on. In addition, whether to perform lateral lymph node dissection depends on patients with lateral lymph node metastasis or part of patients with central lymph node metastasis.

Patients with evidence of nodal disease require therapeutic neck dissection. When disease is restricted to the central compartment, clearance of levels VI and VII is suggested. Therapeutic central-compartment neck dissection for patients with clinically involved central nodes should undergo total thyroidectomy to provide clearance of disease from the central neck. The recurrent laryngeal nerves should be carefully dissected and preserved, and the parathyroid glands should be identified and preserved along with their blood supply. When the parathyroid glands are devascularized, they may require autotransplantation in the sternocleidomastoid muscle. In patients with proven lateral neck disease, therapeutic neck dissection is indicated and can be done in a rather selective manner. Rates of metastasis in levels I, IIb, and Va are low, and are in the absence of proven disease, these levels can be spared to avoid morbidity, especially to the marginal mandibular and spinal accessory nerves. The lateral neck dissection should normally entail levels IIa through $\mathrm{Vb}$ and can be done simply by continuing the thyroidectomy, central neck dissection incision laterally within the same skin crease. In thyroid cancer, special attention should be paid to nodal tissue posterior to the great vessels in level IV, as this is a common site for recurrent nodal disease. Besides, lymph mode metastases are often found very low in the base of the neck, and dissecting this area may increase the risk for substantial vascular and lymphatic injury. ${ }^{28}$

We found that female patients were vulnerable to postoperative hypoparathyroidism. Serum calcium is regulated by 1,25-dihydroxyvitamin D or calcitriol through bone resorption, PTH through calcium reabsorption of renal tubules, and calcitriol through calcium intestinal absorption. ${ }^{29}$ This phenomenon may be attributed to the dropping hormone levels in menopausal women. ${ }^{30,31}$ Previous studies also showed that intrathyroidal parathyroid glands were more frequent in women owing to the high occurrence rates of parathyroid injury and hypocalcemia. ${ }^{32-34}$

In fact, vitamin D level may be a really important preoperative risk factor in predicting the postoperative hypocalcemia. Griffin et $\mathrm{a}^{35}$ found that vitamin D does not play a significant role in the occurrence of postoperative hypocalcemia. This result is in accordance with other studies. ${ }^{36,37}$ Recently, Danan and Shonka ${ }^{26}$ demonstrated that vitamin D level is a significant predictor of postoperative hypocalcemia in patients in whom $\geq 3$ parathyroid glands were identified. However, in our retrospective study, we did not have the data for preoperative vitamin D levels. We believe that this complicated risk factor needs further investigation.

In our analysis, we found that parathyroid autotransplantation is a risk factor for postoperative hypoparathyroidism. Many analyses have demonstrated that parathyroid autotransplantation plays an important role in avoiding permanent hypoparathyroidism and should be a routine surgery. ${ }^{38-40}$ After autotransplantation, grafted parathyroid required time to regain its function. ${ }^{41}$ We also demonstrated that parathyroid autotransplantation increases the risk of postoperative hypoparathyroidism.

It is well known that different types of thyroid disease need appropriate excision extension, which affects operation time. The extent of thyroidectomy, which depends on the pathology and operation method, is significantly related to the frequency of postoperative hypoparathyroidism. ${ }^{42}$ Certainly, isolation of the recurrent laryngeal nerve during surgery can attribute to venous congestion and edema. Besides, ligation of thyroid blood vessels also disrupts the stasis of blood supply. Edema and blood supply stasis have a negative influence on parathyroid function and may induce a transient hypoparathyroidism lasting for $\geq 1$ week after surgery. ${ }^{43}$ In our study, the surgical method played a dominant role in causing postoperative hypoparathyroidism. 
The near-total thyroidectomy and total thyroidectomy were independent risk factors attributing to hypothyroidism $(P=0.001, \mathrm{OR}=10.502$, 95\% CI: 2.726-40.466; $P<0.001$, OR=44.647, 95\% CI: 13.541-147.207). Similarly, Nawrot et $\mathrm{al}^{44}$ have demonstrated that hypoparathyroidism was more frequently seen after total thyroidectomy $(20.2 \%)$ than neartotal thyroidectomy $(6.7 \%)$ or subtotal thyroidectomy $(4.1 \%)$. González-Botas and Piedrahita ${ }^{45}$ and Merchavy et $\mathrm{al}^{46}$ have reported that postoperative hypocalcemia was less common in patients with completion thyroidectomy than in patients who underwent total thyroidectomy.

Shen et $\mathrm{al}^{47}$ have demonstrated that the incidence of hypoparathyroidism was statistically significant between patients who underwent thyroidectomy with or without neck lymph node dissection. Similarly, we found that patients with lateral lymph node dissected showed a higher incidence of hypocalcemia and hypoparathyroidism than those without receiving lateral lymph node dissection ( $P=0.017 ; P=0.038)$. Actually, parathyroid blood vessels are thin, fragile, and terminal; parathyroid blood supply is easily affected or disrupted, which may result in the high occurrence of hypocalcemia after lateral lymph node dissection. ${ }^{48}$

$\mathrm{CN}$ suspension injection is applied for helping identify lymph nodes in lymph node dissection, including breast cancer and gastrointestinal cancer. ${ }^{49-51}$ Because the components for $\mathrm{CN}$ suspension injections are nanocarbon granules, these have diameters of $150 \mathrm{~nm}$ and they can enter lymphatic capillaries (diameters of $500 \mathrm{~nm}$ ) rather than blood vessel capillaries (diameters of 30-50 nm) and immediately enter into drainage lymph nodes. ${ }^{52}$ Furthermore, recent studies have shown that $\mathrm{CN}$ suspension injection can aid in identifying parathyroid glands, which may provide a new strategy for identification and protection during parathyroid surgery. ${ }^{52,53}$

\section{Results}

Our results have shown, with the aid of $\mathrm{CN}$ suspension, that incidence of hypocalcemia and hypoparathyroidism is lower, which implies that CNs could help to distinguish the parathyroid glands from thyroid tissue. This result is in accordance with previous research..$^{54,55}$

\section{Conclusion}

Postoperative hypocalcemia and hypoparathyroidism incidence were significantly related to the extent of thyroidectomy, gender, lateral lymph node dissection, operative time, and use of CNs. These findings were crucial for guiding surgeons to prevent the occurrence of hypocalcemia and hypoparathyroidism.

\section{Acknowledgments}

This study was funded by the Key Project of Science and Technology Innovation Team of Zhejiang Province (No. 2013TD10) and the National Natural Science Foundation of China (No. 81372380).

The data sets supporting the conclusions of this article are included within this article. Raw data are available on the main electronic data storage system of First Affiliated Hospital of Wenzhou Medical University, and access can be provided upon request to the authors.

\section{Disclosure}

The authors report no conflicts of interest in this work.

\section{References}

1. Davies L, Welch HG. Increasing incidence of thyroid cancer in the United States, 1973-2002. JAMA. 2006;295(18):2164-2167.

2. Roman BR, Morris LG, Davies L. The thyroid cancer epidemic, 2017 perspective. Curr Opin Endocrinol Diabetes Obes. 2017;24(5):332-336.

3. Carling T, Udelsman R. Thyroid cancer. Annu Rev Med. 2014;65:125-137.

4. Wilson C. Surgery: benign thyroid disease-total or subtotal thyroidectomy? Nat Rev Endocrinol. 2012;8(1):4.

5. Bilimoria KY, Bentrem DJ, Ko CY, et al. Extent of surgery affects survival for papillary thyroid cancer. Ann Surg. 2007;246(3):375-381; discussion 381-384

6. Christou N, Mathonnet M. Complications after total thyroidectomy J Visc Surg. 2013;150(4):249-256.

7. Daher R, Lifante JC, Voirin N, et al; CATHY Study Group. Is it possible to limit the risks of thyroid surgery? Ann Endocrinol. 2015;76(1 suppl 1):S16-S26.

8. Asari R, Passler C, Kaczirek K, Scheuba C, Niederle B. Hypoparathyroidism after total thyroidectomy: a prospective study. Arch Surg. 2008;143(2):132-137; discussion 138.

9. Pisanu A, Saba A, Coghe F, Uccheddu A. Early prediction of hypocalcemia following total thyroidectomy using combined intact parathyroid hormone and serum calcium measurement. Langenbecks Arch Surg. 2013;398(3):423-430.

10. Al-Qurayshi Z, Hauch A, Srivastav S, Aslam R, Friedlander P, Kandil E. A national perspective of the risk, presentation, and outcomes of pediatric thyroid cancer. JAMA Otolaryngol Head Neck Surg. 2016;142(5):472-478.

11. Bhattacharyya N, Fried MP. Assessment of the morbidity and complications of total thyroidectomy. Arch Otolaryngol Head Neck Surg. 2002;128(4):389-392.

12. Vashishta R, Mahalingam-Dhingra A, Lander L, Shin EJ, Shah RK. Thyroidectomy outcomes: a national perspective. Otolaryngol Head Neck Surg. 2012;147(6):1027-1034

13. Jumaily JS, Noordzij JP, Dukas AG, et al. Prediction of hypocalcemia after using 1- to 6-hour postoperative parathyroid hormone and calcium levels: an analysis of pooled individual patient data from 3 observational studies. Head Neck. 2010;32(4):427-434.

14. AES Guidelines 06/01 Group. Australian Endocrine Surgeons Guidelines AES06/01. Postoperative parathyroid hormone measurement and early discharge after total thyroidectomy: analysis of Australian data and management recommendations. ANZ J Surg. 2007;77(4):199-202.

15. Puzziello A, Rosato L, Innaro N, et al. Hypocalcemia following thyroid surgery: incidence and risk factors. A longitudinal multicenter study comprising 2,631 patients. Endocrine. 2014;47(2):537-542.

16. Garrahy A, Murphy MS, Sheahan P. Impact of postoperative magnesium levels on early hypocalcemia and permanent hypoparathyroidism after thyroidectomy. Head Neck. 2016;38(4):613-619. 
17. Gross ND. Postoperative hypocalcemia-the difference a definition makes. Commentary. Head Neck. 2010;32(3):283-284.

18. Reeve T, Thompson NW. Complications of thyroid surgery: how to avoid them, how to manage them, and observations on their possible effect on the whole patient. World J Surg. 2000;24(8):971-975.

19. American Thyroid Association (ATA) Guidelines Taskforce on Thyroid Nodules and Differentiated Thyroid Cancer, Cooper DS, Doherty GM, et al. Revised American Thyroid Association management guidelines for patients with thyroid nodules and differentiated thyroid cancer. Thyroid. 2009;19(11):1167-1214.

20. Zhu J, Tian W, Xu Z, et al. Expert consensus statement on parathyroid protection in thyroidectomy. Ann Transl Med. 2015;3(16):230.

21. Magreni A, Bann DV, Schubart JR, Goldenberg D. The effects of race and ethnicity on thyroid cancer incidence. JAMA Otolaryngol Head Neck Surg. 2015;141(4):319-323.

22. Puzziello A, Gervasi R, Orlando G, Innaro N, Vitale M, Sacco R. Hypocalcaemia after total thyroidectomy: could intact parathyroid hormone be a predictive factor for transient postoperative hypocalcemia? Surgery. 2015;157(2):344-348.

23. Sousa Ade A, Salles JM, Soares JM, Moraes GM, Carvalho JR, SavassiRocha PR. Predictors factors for post-thyroidectomy hypocalcaemia. Rev Col Bras Cir. 2012;39(6):476-482.

24. Page C, Strunski V. Parathyroid risk in total thyroidectomy for bilateral, benign, multinodular goitre: report of 351 surgical cases. J Laryngol Otol. 2007;121(3):237-241.

25. Rosato L, Avenia N, Bernante P, et al. Complications of thyroid surgery: analysis of a multicentric study on 14,934 patients operated on in Italy over 5 years. World J Surg. 2004;28(3):271-276.

26. Danan D and Shonka DC, Jr. Preoperative vitamin D level as predictor of post-thyroidectomy hypocalcemia in patients sustaining transient parathyroid injury. Head Neck. 2017;39(7):1378-1381.

27. Trupka A, Sienel W. [Autotransplantation of at least one parathyroid gland during thyroidectomy in benign thyroid disease minimizes the risk of permanent hypoparathyroidism]. Zentralbl Chir. 2002;127(5):439-442.

28. Ito Y, Higashiyama T, Takamura Y, et al. Risk factors for recurrence to the lymph node in papillary thyroid carcinoma patients without preoperatively detectable lateral node metastasis: validity of prophylactic modified radical neck dissection. World J Surg. 2007;31(11): 2085-2091.

29. Rizzoli R, Bonjour J. [Calciotropic hormones and integrated regulation of calcemia and calcium balance]. Rev Prat. 1998;48(11): $1178-1184$

30. Nellis JC, Tufano RP, Gourin CG. Association between magnesium disorders and hypocalcemia following thyroidectomy. Otolaryngol Head Neck Surg. 2016;155(3):402-410.

31. Sands NB, Payne RJ, Côté V, Hier MP, Black MJ, Tamilia M. Female gender as a risk factor for transient post-thyroidectomy hypocalcemia. Otolaryngol Head Neck Surg. 2011;145(4):561-564.

32. Gonçalves Filho J, Kowalski LP. Surgical complications after thyroid surgery performed in a cancer hospital. Otolaryngol Head Neck Surg. 2005;132(3):490-494.

33. Lin DT, Patel SG, Shaha AR, Singh B, Shah JP. Incidence of inadvertent parathyroid removal during thyroidectomy. Laryngoscope. 2002;112(4):608-611.

34. Manouras A, Markogiannakis H, Lagoudianakis E, et al. Unintentional parathyroidectomy during total thyroidectomy. Head Neck. 2008;30(4):497-502.

35. Griffin TP, Murphy MS, Sheahan P. Vitamin D and risk of postoperative hypocalcemia after total thyroidectomy. JAMA Otolaryngol Head Neck Surg. 2014;140(4):346-351.
36. Salinger EM, Moore JT. Perioperative indicators of hypocalcemia in total thyroidectomy: the role of vitamin D and parathyroid hormone. Am J Surg. 2013;206(6):876-881; discussion 881-882.

37. Falcone TE, Stein DJ, Jumaily JS, et al. Correlating pre-operative vitamin D status with post-thyroidectomy hypocalcemia. Endocr Pract. 2015;21(4):348-354.

38. Zedenius J, Wadstrom C, Delbridge L. Routine autotransplantation of at least one parathyroid gland during total thyroidectomy may reduce permanent hypoparathyroidism to zero. Aust NZJ Surg. 1999;69(11):794-797.

39. Palazzo FF, Sywak MS, Sidhu SB, Barraclough BH, Delbridge LW. Parathyroid autotransplantation during total thyroidectomy - does the number of glands transplanted affect outcome? World J Surg. 2005;29(5):629-631.

40. Shaha AR, Jaffe BM. Parathyroid preservation during thyroid surgery. Am J Otolaryngol. 1998;19(2):113-117.

41. Paek SH, Lee YM, Min SY, Kim SW, Chung KW, Youn YK. Risk factors of hypoparathyroidism following total thyroidectomy for thyroid cancer. World J Surg. 2013;37(1):94-101.

42. Rajinikanth J, Paul M, Abraham DT, Selvan CB, Nair A. Surgical audit of inadvertent parathyroidectomy during total thyroidectomy: incidence, risk factors, and outcome. Medscape J Med. 2009;11(1):29.

43. Sakorafas GH, Stafyla V, Bramis C, Kotsifopoulos N, Kolettis T, Kassaras G. Incidental parathyroidectomy during thyroid surgery: an underappreciated complication of thyroidectomy. World J Surg. 2005;29(12):1539-1543.

44. Nawrot I, Pragacz A, Pragacz K, Grzesiuk W, Barczyński M. Total thyroidectomy is associated with increased prevalence of permanent hypoparathyroidism. Med Sci Monit. 2014;20:1675-1681.

45. González-Botas JH, Piedrahita DL. Hypocalcaemia after total thyroidectomy: incidence, control and treatment. Acta Otorrinolaringol Esp. 2013;64(2):102-107.

46. Merchavy S, Marom T, Forest VI, et al. Comparison of the incidence of postoperative hypocalcemia following total thyroidectomy vs completion thyroidectomy. Otolaryngol Head Neck Surg. 2014;152(1):53-56.

47. Shen WT, Ogawa L, Ruan D, et al. Central neck lymph node dissection for papillary thyroid cancer: comparison of complication and recurrence rates in 295 initial dissections and reoperations. Arch Surg. 2010;145(3):272-275.

48. Cheah WK, Arici C, Ituarte PH, Siperstein AE, Duh Q-Y, Clark OH. Complications of neck dissection for thyroid cancer. World J Surg. 2002;26(8):1013-1016.

49. Ge J, Yan B, Cao XC. [Comparison of sentinel lymph node detection by methylene blue and carbon nanoparticle suspension injection in early breast cancer]. Zhonghua Zhong Liu Za Zhi. 2011;33(3):226-228.

50. Cai HK, He HF, Tian W, Zhou MQ, Hu Y, Deng YC. Colorectal cancer lymph node staining by activated carbon nanoparticles suspension in vivo or methylene blue in vitro. World J Gastroenterol. 2012;18(42):6148-6154.

51. Wang YN, Li GP, Gong W, et al. [Application of (9)(9)mTc-SPECT$\mathrm{CT}$ and carbon nanoparticles suspension injection in sentinel lymph node mapping for rectal cancer]. Zhonghua Wei Chang Wai Ke Za Zhi. 2011;14(5):352-355

52. Huang K, Luo D, Huang M, Long M, Peng X, Li H. Protection of parathyroid function using carbon nanoparticles during thyroid surgery. Otolaryngol Head Neck Surg. 2013;149(6):845-850.

53. Wang XL, Wu YH, Xu ZG, Ni S, Liu J. [Parathyroid glands are differentiated from lymph node by activated-carbon particles]. Zhonghua Er Bi Yan Hou Tou Jing Wai Ke Za Zhi. 2009;44(2):136-140.

54. Yu W, Zhu L, Xu G, Song Y, Li G, Zhang N. Potential role of carbon nanoparticles in protection of parathyroid glands in patients with papillary thyroid cancer. Medicine (Baltimore). 2016;95(42):e5002.

55. Gao B, Tian W, Jiang Y, et al. Application of carbon nanoparticles for parathyroid protection in reoperation of thyroid diseases. Int J Clin Exp Med. 2015;8(12):22254-22261. 
Cancer Management and Research

\section{Publish your work in this journal}

Cancer Management and Research is an international, peer-reviewed open access journal focusing on cancer research and the optimal use of preventative and integrated treatment interventions to achieve improved outcomes, enhanced survival and quality of life for the cancer patient

The manuscript management system is completely online and includes

Submit your manuscript here: https://www.dovepress.com/cancer-management-and-research-journal

a very quick and fair peer-review system, which is all easy to use. Visit $\mathrm{http}: / / \mathrm{www}$.dovepress.com/testimonials.php to read real quotes from published authors. 